\title{
PEMBERDAYAAN EKONOMI PEREMPUAN \\ MELALUI QARD AL-HASAN PADA KOPERASI SIMPAN PINJAM WANITA MAJU JAYA KEBALANPELANG BABAT LAMONGAN
}

\author{
Ahmad Ubaidillah; Misbahul Khoir \\ Universitas Islam Lamongan \\ e-mail: ubaidmad@yahoo.com; misbah.coy@gmail.com
}

\begin{abstract}
One of the ways to improve women's economy is cooperatives. The basic objective of women-oriented cooperatives is to empower Indonesian women to contribute to efforts to improve the economic status and welfare of their families. This effort at the same time strengthens the independence of women so that they have strong bargaining power and can make a large contribution to the improvement of the national economy. The role of the qard al-hasan contract in the Maju Jaya Women's Savings and Loan Cooperative, Kebalanpelang Village, Babat Lamongan towards women's economic empowerment from women's businesses to create income to support their family's economy. This research is a qualitative research with an investigative pattern in which data and statements are obtained from the results of direct interaction between the researcher and the object under study and the people at the research site. The sampling technique used was purposive sampling and snowball sampling. The data collection techniques used include observation, documentation, and interviews. The data analysis technique uses the Miles and Huberman model. The results showed that the qard al-hasan contract applied in the Maju Jaya Women's Savings and Loan Cooperative can also improve the quality of women's economic enterprises for the welfare of women in the village of Kebalanpelang Babat Lamongan. Because with the qard al-hasan contract, this is one way to help and ease the burden on women who have businesses in capital problems which aim to increase their business to be better and develop than before, so that by means of increasing their business income they earn them. ownership also automatically increases so that women can help their family's economy.
\end{abstract}

Keywords: qard al-hasan; women's savings and loan cooperatives; income

\section{Pendahuluan}

Jumlah penduduk Indonesia pada tahun 2018 adalah 265 juta jiwa. Presentase penduduk perempuan sebesar 49,43 persen sedangkan laki-laki sebesar 50,57 persen. Jumlah tersebut menunjukkan bahwa secara nasional penduduk perempuan lebih sedikit dibandingkan lakilaki. Jika dilihat berdasarkan daerah tempat tinggal, baik di perkotaan maupun di perdesaan, penduduk perempuan di perkotaan sebesar 63,37 persen lebih tinggi dibandingkan dengan yang berada di perdesaan, yaitu 65,06 persen. Jumlah perempuan yang hampir mencapai setengah dari total penduduk Indonesia merupakan potensi yang sangat besar dan harus dimanfaatkan dengan baik agar kaum perempuan tidak tertindas. ${ }^{1}$

\footnotetext{
1 Siti Hanisah, "Pemberdayaan Perempuan Melalui Kegiatan Ekonomi Berkeadilan", Jurnal Perempuan Indonesia, Volume 9, Nomor 1 (Oktober, 2013), 72.
} 
Pemberdayaan ini sangat penting karena dapat menciptakan kondisi, suasana, iklim, yang memungkinkan potensi masayarakat untuk berkembang. Untuk mencapai tujuan pemberdayaan bisa dilakukan dengan berbagai macam strategi, di antaranya strategi modernisasi yang mengarah pada perubahan struktur sosial, ekonomi, dan budaya yang bersumber dari peran serta masyarakat. Prioritas utama dalam pemberdayaan adalah terciptanya kemandirian. ${ }^{2}$

Pemberdayaan perempuan dalam konteks kebijakan sesuai dengan Inpres Nomor 9 tahun 2000 tentang pengarusutamaan gender, yaitu kebijakan dapat mengintegrasikan pengalaman, kebutuhan dan perempuan dan laki-laki ke dalam proses perencanaan, pelaksanaan, pemantauan dan evaluasi kebijakan, program, peraturan serta anggaran dalam segala bidang (politik, ekonomi, sosial budaya, hukum, pertahanan, keamanan dan kemasyarakatan). Ini berarti pemberdayaan perempuan harus terintegrasi antara pemberdayaan ekonomi dan kebijakan bagi perempuan.

Keberhasilan pemberdayaan terhadap perempuan bisa merujuk pada lima indikator. Pertama, meningkatnya kemampuan kaum perempuan untuk melibatkan diri dalam pembangunan. Kedua, program pembangunan sebagai partisipan aktif (subyek) agar tidak sekedar menjadi obyek pembangunan. Ketiga, meningkatkan kaum perempuan untuk melibatkan diri dalam kepemimpinan untuk meningkatkan posisi tawar menawar dan keterlibatan dalam setiap program pembangunan, baik perencana, pelaksana, maupun pemantauan dan evaluasi kegiatan. Keempat, meningkatkan kemampuan kaum perempuan dalam mengelola usaha skala rumah tangga, industri kecil maupun besar untuk menunjang kebutuhan rumah tangga, maupun untuk membuka peluang kerja produktif dan mandiri. Kelima, meningkatkan peran dan fungsi organisasi perempuan di tingkat lokal sebagai wadah pemberdayaan kaum perempuan agar dapat terlibat secara aktif dalam program pembangunan pada wilayah tempat tinggalnya. ${ }^{3}$

Salah satu contoh desa yang sudah menerapkan pemberdayaan ekonomi perempuan adalah Desa Kebalanpelang Babat Lamongan. Program pemberdayaan ekonomi perempuan berupaya untuk menciptakan lapangan pekerjaan bagi perempuan khususnya di Desa Kebalanpelang yang mayoritas kaum perempuan sudah mempunyai ketrampilan berwirausaha, seperti menjahit dan mengelola berbagai macam makanan untuk dijadikan cemilan dan dipasarkan di toko-toko kecil maupun secara online.

Qard al-hasan disediakan bukan untuk tujuan profit melainkan sosial, sebuah produk pembiayaan yang bernuansa sosial dalam upaya mensejahterakan rakyat kecil dan mengurangi ketimpangan ekonomi yang terjadi di masyarakat. Yakni dengan menjadikan dana hasil realisasi pembiayaan produk tersebut (qard al-ḥasan) sebagai modal usaha, sekalipun kecil-kecilan. ${ }^{4}$

Kaum perempuan di Desa Kebalanpelang ini mempunyai pekerjaan beragam yang berjalan di rumah, seperti penjahit, produksi jajanan atau cemilan, membuat kulit pangsit,

\footnotetext{
${ }^{2}$ http://mazdalifahjalil.wordpress.com/2013/01/25/seminar-dan-talkshow-perempuan-danruang- publik/ diakses pada 24 Desember 2019.

${ }^{3}$ Ardiyati. "Analisis Pemberdayaan Perempuan Melalui Simpan Pinjam Kelompok" Publikauma: Jurnal Ilmu Administrasi Publik, Volume 6, Nomor 1 (2018), 92.

${ }^{4}$ Burhanudin, "Pemahaman dan Penerapan Qard al-Hasan Pada KJKS BMT Haniva" (Skripsi--UIN Sunan Kalijaga Yogyakarta, 2012), 5.
} 
membuka toko peracangan dan sebagian juga ada yang dipasarkan secara online untuk memperluas promosi dari produksi mereka, dan semua itu diawali dengan meminjam modal usaha dari Koperasi Simpan Pinjam (KSP) Wanita Maju Jaya yang menggunakan akad qard al-hasan yang tersedia di koperasi desa tersebut.

Penelitian ini bertujuan mengetahui bagaimana akad qard al-hasan di KSP Wanita Maju Jaya Desa Kebalanpelang Babat Lamongan dapat membantu para kaum perempuan untuk masalah modal dalam membangun usahanya. Berdasarkan manfaaat, penelitian ini diharapkan memiliki kontribusi yang cukup penting, baik dari sisi teoritis maupun praktis. Dari sisi teoritis, penelitian ini bisa memperkaya wawasan terkait peran akad qard al-hasan di KSP Wanita Maju Jaya dalam membantu para kaum perempuan untuk masalah modal dalam membangun usahanya. Dari sisi praktis, penelitian ini bisa dijadikan sebagai proyek percontohan bagi masyarakat desa-desa lain bagaimana menerapkan dan mengembangkan akad qard al-hasan di KSP Wanita Maju Jaya untuk membantu para kaum perempuan terkait masalah modal dalam pengembangan usaha.

\section{Metode Penelitian}

Penelitian ini merupakan penilitian kualitatif dengan pendekatan deskriptif analitis, yaitu suatu pendekatan yang bertujuan untuk mendeskripsikan atau memberi gambaran umum terhadap suatu objek penelitian yang diteliti melalui data yang telah terkumpul dan membuat kesimpulan yang berlaku umum. Sumber data primer diambil dengan melakukan observasi dan wawancara dengan ketua, pengurus, dan anggota Koperasi Simpan Pinjam (KSP) Wanita Maju Jaya di Desa Kebalanpelang Babat Lamongan. Sedangkan sumber data sekunder didapatkan dari catatan laporan pembiayaan, dokumentasi keuangan koperasi, jumlah nasabah pembiayaan akad qard al-hasan, buku-buku pedoman dan jurnal pemberdayaan ekonomi perempuan dan akad qard al-hasan.

Untuk teknik pengumpulan data, dilakukan dengan cara observasi, wawancara, dan dokumentasi. Sedangkan teknik analisis data menggunakan teknik analisis data kualitatif model Miles dan Huberman, yaitu proses analisis yang mendasarkan pada adanya semantis antar variabel yang sedang diteliti. Langkah-langkah yang ditempuh dalam menganalisa data kualitatif adalah redukasi data, penyajian data, dan penarikan kesimpulan dan verifikasi. ${ }^{5}$ Sedangkan untuk keabsahan data, menggunakan teknik triangulasi, yaitu teknik pemeriksaan keabsahan data yang memanfaatkan sesuatu yang lain. Di luar data itu untuk keperluan pengecekan sebagai pembanding terhadap data itu. ${ }^{6}$

\section{Gambaran Umum Koperasi Simpan Pinjam Wanita Maju Jaya}

Koperasi Simpan Pinjam (KSP) Wanita Maju Jaya merupakan salah satu koperasi yang mempunyai jenis usaha simpan pinjam. Koperasi ini berada di Desa Kebalanpelang Kecamatan Babat Kabupaten Lamongan dan mulai berdiri secara resmi tanggal 31 maret 2010 dengan Nomor Induk Koperasi 3524100110042, dan Nomor Badan Hukum 518/BH/XVI.10/372/413.111/2010.

\footnotetext{
${ }^{5}$ Lexy J. Moleong, Metodologi Penelitian Kualitatif (Bandung: PT. Remaja Rosdakarya, 2012), 253.

${ }^{6}$ Ibid., 330.
} 
KSP Wanita Maju Jaya merupakan lembaga non bank dengan modal awal yang diberikan oleh pemerintah daerah sebesar Rp. 25.000.000,- dengan jumlah anggota awal 33 orang, dan dengan berjalanya waktu anggota yang tergabung di KSP Wanita Maju Jaya sekarang berjumlah 137 anggota kaum perempuan dan mendapat tambahan modal yang kedua dari APBD sebesar Rp. 30.000.000,-. Jadi total modal KSP Wanita Maju Jaya di Desa Kebalanpelang Kecamatan Babat Kabupaten Lamongan adalah Rp. 55.000.000,-. Dengan banyaknya jumlah anggota yang bergabung di KSP Wanita Maju Jaya maka jumlah transaksi yang harus ditangani koperasi juga menjadi semakin banyak. Modal awal setelah melakukan observasi pada KSP Wanita Maju Jaya diketahui bahwa koperasi tersebut hanya melakukan transaksi simpan pinjam satu bulan sekali saja dan hanya di awal bulan anggota melakukan angsuran pinjaman pada KSP Wanita Maju Jaya. KSP Wanita Maju Jaya yang berada di Desa Kebalanpelang ini merupakan salah satu contoh bagaimana peran dan kekuatan perempuan dalam pengembangan ekonomi. Dengan langkah perlahan namun pasti, koperasi perempuan ini terus merangkak berkembang. Biasanya koperasi didirikan atas dasar adanya kebutuhan, dan kepentingan yang sama, yaitu dalam upaya menambah penghasilan, memberdayakan dan meningkatkan perekenomian keluarga. ${ }^{7}$

Berangkat dari kepentingan bersama, roda koperasi yang sejak awal bergerak melalui penawaran produk simpan pinjam wanita tanpa bunga. Keuntungan dari modal bersifat pinjaman lunak (qard al-hasan), sehingga sistem yang digunakan dalam simpan pinjam ini bersifat adil dan islami atau bersifat syar'i, artinya bahwa KSP Wanita Maju Jaya tidak memberatkan terhadap anggotanya, akan tetapi justru sebaliknya untuk meningkatkan taraf perekonomian para kaum perempuan.

\section{Akad Qarḍ al-Hasan di Koperasi Simpan Pinjam Wanita Maju Jaya}

Akad qarḍ al-ḥasan adalah pinjaman dana kepada anggota yang pengembaliannya tanpa dibebankan kelebihan. Pengembalian pinjaman sebesar pinjaman yang diberikan tanpa adanya kelebihan dalam bentuk apapun. Akad yang dibuat pada prinsipnya adalah saling membantu dalam penyediaan dana segera. Dengan akad qard al-ḥasan, peminjam hanya wajib mengembalikan pokoknya saja tanpa ada tambahan biaya apapun.

Proses awal yang dilakukan, sebagaimana hasil dari wawancara dengan Sri Sumirahani selaku ketua KSP Wanita Maju Jaya adalah permohonan pembiayaan oleh anggota dan calon anggota kepada pengurus koperasi. Di sini calon anggota akan datang langsung ke koperasi setelah itu pihak pengurus koperasi akan memberikan penjelasan kepada anggota tentang akad qard al-hasan itu sendiri serta hak dan kewajiban yang akan dipenuhi calon anggota setelah pengajuan disetujui. Setelah calon anggota setuju, pengurus akan memberikan formulir pendaftaran atau permohonan beserta persyaratan lengkap yang harus dipenuhi oleh calon anggota. ${ }^{8}$

Langkah berikutnya, yaitu pihak koperasi akan melakukan survey untuk menyesuaikan antara data dan kenyataan di lapangan. Yang disurvey oleh pihak pengurus koperasi adalah usaha dari calon anggota yang akan melakukan pengajuan pembiayaan. Hasil dari survey tersebut diserahkan pada ketua KSP Wanita Maju Jaya sebagai pertimbangan layak atau tidak

\footnotetext{
${ }^{7}$ Sumarni, Wawancara, Lamongan, 13 Maret 2020.

${ }^{8}$ Sri Sumirahani, Wawancara, Lamongan, 13 Maret 2019.
} 
untuk diterima sebagai anggota koperasi. Dan setelah dinyatakan layak maka proses penandatanganan akad qard al-hasan sekaligus serah terima jaminam dari anggota akan dilakukan. Setelah akad qard al-hasan dilakukan kemudian pengurus koperasi akan meminta anggota untuk menandatangani berkas persetujuan pembayaran, dan setelah itu dana akan dicairkan. ${ }^{9}$

KSP Wanita Maju Jaya di Desa Kebalanpelang Babat Lamongan selalu mengalami peningkatan jumlah anggota yang melakukan pembiayaan melalui akad qard al-ḥasan setiap tahunnya. Ini menandakan bahwa pembiayaan qard al-hasan berkembang semakin baik di KSP Wanita Maju Jaya.

\section{Peranan Qard al-Hasan di Koperasi Simpan Pinjam Wanita Sebagai Media Pemberdayaan Ekonomi Perempuan}

Akad qard al-hasan sudah dilakukan sejak tahun 2014 di Koperasi Simpan Pinjam (KSP) Wanita Maju Jaya Desa Kebalanpelang Babat Lamongan. Sumber dana awal qard alhasan diperoleh dari dana APBD. Tidak semua pengajuan akan dikabulkan oleh pihak KSP Wanita Maju Jaya, hanya para kaum perempuan saja yang diberikan pinjaman karena alasan untuk usaha.

Selain diindetifikasi sebagai lembaga keuangan atau bisnis, KSP Wanita Maju Jaya juga sering dipahami sebagai lembaga sosial. Pada satu kesempatan KSP Wanita Maju Jaya dapat menginvestasikan dananya untuk lebih mengembangkan bisnisnya, tetapi pada saat yang lain KSP Wanita Maju Jaya juga bisa mengembangkan dirinya untuk membantu dalam penyelesaian masalah-masalah sosial, terutama kebutuhan kaum perempuan yang bersifat konsumtif.

Pada peran yang pertama, KSP Wanita Maju Jaya dapat diidentifikasi sebagai lembaga sosial, yakni lembaga yang berperan untuk ikut menyelesaikan masalah sosial, terutama masalah ekonomi yang sedang dihadapi oleh kaum perempuan. Hal ini berarti bahwa KSP Wanita Maju Jaya bisa menempatkan dirinya sebagai bagian dari lembaga yang dapat mengadvokasi masalah kebutuhan kaum perempuan yang bersifat konsumtif.

Peran KSP Wanita Maju Jaya ini antara lain dapat diwujudkan dalam bentuk adanya produk atau akad qard al-hasan, yakni pinjaman yang diberikan oleh KSP Wanita Maju Jaya kepada kaum perempuan dan mereka hanya perlu mengembalikan pinjaman pokoknya saja tanpa ada tambahan apapun. Produk ini dianggap sebagai bentuk kebaikan yang diberikan koperasi untuk kaum perempuan, sehingga dengan adanya akad qard al-ḥasan kaum perempuan bisa dengan mudah mendapatkan pinjaman untuk modal usaha mereka. ${ }^{10}$

Qard al-hasan di KSP Wanita Maju Jaya merupakan bagian dari mekanisme kerja yang lebih menonjolkan peran sosial dan non profit. Namun demikian, hal ini tidak lantas berarti KSP Wanita Maju Jaya harus mengalami kerugian. Salah satu upaya untuk meminimalisir kerugian yang mungkin akan dialami oleh KSP Wanita Maju Jaya dalam akad qard al-hasan ini dapat dilakukan dengan menetapkan bahwa biaya admisitrasi sepenuhnya ditanggung oleh anggota koperasi.

\footnotetext{
${ }^{9}$ Khoirun, Wawancara, Lamongan, 20 Maret 2019.

${ }^{10}$ Sri Sumirahani, Wawancara, Lamongan, 19 Maret 2019.
} 


\section{Peningkatan Pendapatan Kaum Perempuan Setelah Melakukan Pembiayaan Qard al- Hasan di Koperasi Simpan Pinjam Wanita Maju Jaya}

Pendapatan adalah sejumlah penghasilan yang diperoleh masyarakat atas prestasi kerjanya dalam periode tertentu, baik harian, mingguan, bulanan maupun tahunan. Usahausaha mikro yang dimiliki oleh kaum perempuan di Desa Kebalanpelang Babat Lamongan rata-rata memiliki tujuan untuk bisa membantu perekonomian rumah tangga, semakin banyaknya pengeluaran yang mereka lakukan setiap bulanya maka mereka juga semakin ingin meningkatkan pendapatanya agar selalu bisa mencukupi kebutuhan dalam kehidupan seharihari.

Pendapatan kaum perempuan di Desa Kebalanpelang Babat Lamongan merupakan suatu kemampuan yang dimilikinya melalui adanya peningkatan daya beli keluarga untuk membiayai kebutuhan dalam sehari-hari baik kebutuhan dasar, kebutuhan sosial maupun kebutuhan lainya yang terlihat dari peningkatan pendapatan keluarga, pengeluaran keluarga (kemampuan daya beli) dan perkembangan tabungan keluarga.

Peningkatan pendapatan yang mereka alami tidak menjadikan para kaum perempuan lupa dengan tugas mereka menjadi ibu rumah tangga, oleh karena itu usaha yang mereka jalani tidak terlalu berat dan memakan banyak waktu yang membuat kaum perempuan tidak bisa mengurus anak, suami dan pekerjaan rumah. Meskipun di awal mereka membangun usaha dengan modal yang pas-pasan tetapi semenjak mereka menjalankan usaha juga mulai meminjam tambahan modal di KSP Wanita Maju Jaya yang menyediakan akad qard al-hasan di mana dengan adanya akad ini usaha mereka bisa berkembang dan bisa berjalan terus untuk meningkatkan pendapatan. ${ }^{11}$

Timbulnya keinginan untuk memulai usaha adalah karena para kaum perempuan Desa Kebalanpelang Babat Lamongan banyak yang merasa bahwa perekonomian dalam rumah tangga mereka bisa dikatakan kurang untuk mencukupi kebutuhanya, sedangkan pada zaman sekarang harga apapun naik, sehingga beberapa ibu rumah tangga memiliki ide untuk memulai usaha-usaha kecil di rumah, sedangkan untuk memulai usaha itu juga harus disertai dengan adanya modal awal untuk membangun sebuah usaha tersebut.

Pendapatan perekonomian kaum perempuan sesudah dan sebelum melakukan pembiayaan akad qard al-ḥasan di KSP Wanita Maju Jaya dapat dikatakan mengalami perubahan. Untuk mengetahui sejauh mana keberhasilan KSP Wanita Maju Jaya Kebalanpelang dalam menjalankan perannya, berikut data yang disampaikan dalam bentuk tabel.

Tabel 1.1. Daftar Modal dan Pendapatan Anggota KSP Wanita Maju Jaya Sebelum dan Sesudah Menggunakan Qard al-Hasan

\begin{tabular}{|c|l|c|c|c|c|}
\hline No & $\begin{array}{c}\text { Nama } \\
\text { Anggota }\end{array}$ & $\begin{array}{c}\text { Modal sebelum } \\
\text { qard al-hasan } \\
\text { (rupiah) }\end{array}$ & $\begin{array}{c}\text { Pendapatan } \\
\text { sebelum } \\
\text { qarḍ al-hasan } \\
\text { (rupiah) }\end{array}$ & $\begin{array}{c}\text { Modal sesudah } \\
\text { qard al-hasan } \\
\text { (rupiah) }\end{array}$ & $\begin{array}{c}\text { Pendapatan } \\
\text { sesudah } \\
\text { qarḍ al-hasan } \\
\text { (rupiah) }\end{array}$ \\
\hline 1 & Kasiyatun & 700.000 & 1.000 .000 & 1.500 .000 & 2.000 .000 \\
\hline 2 & Ida & 1.000 .000 & 1.550 .000 & 2.800 .000 & 3.300 .000 \\
\hline
\end{tabular}

${ }^{11}$ Hanik, Wawancara, Lamongan, 15 Juli 2019. 


\begin{tabular}{|c|l|r|r|r|r|}
\hline 3 & Indartik & 4.000 .000 & 6.000 .000 & 8.000 .000 & 10.700 .000 \\
\hline 4 & Wiwik & 1.000 .000 & 1.700 .000 & 2.500 .000 & 3.800 .000 \\
\hline 5 & Masning & 1.200 .000 & 2.000 .000 & 3.500 .000 & 5.300 .000 \\
\hline 6 & Nurul & 2.500 .000 & 3.200 .000 & 5.000 .000 & 7.300 .000 \\
\hline 7 & Nur sholihah & 2.500 .000 & 3.100 .000 & 4.500 .000 & 6.500 .000 \\
\hline 8 & Masnah & 2.000 .000 & 2.800 .000 & 4.000 .000 & 5.700 .000 \\
\hline 9 & Atika & 1.700 .000 & 2.300 .000 & 3.500 .000 & 5.800 .000 \\
\hline 10 & Nikmah & 2.000 .000 & 2.700 .000 & 3.500 .000 & 4.600 .000 \\
\hline
\end{tabular}

Adapun data di atas merupakan data anggota yang menggunakan akad qard al-hasan pada tahun 2018 sampai sekarang. Timbulnya keinginan untuk memulai usaha adalah karena para kaum perempuan di Desa Kebalanpelang Babat Lamongan banyak yang merasa bahwa perekonomian dalam rumah tanga mereka bisa dikatakan kurang untuk mencukupi kebutuhanya, sedangkan pada zaman sekarang harga apapun naik, sehingga beberapa ibu rumah tangga memiliki ide untuk memulai usaha-usaha kecil di rumah, sedangkan untuk memulai usaha itu juga harus disertai dengan adanya modal awal untuk membangun sebuah usaha tersebut. ${ }^{12}$

Ada beberapa faktor yang menyebabkan pendapatan mereka meningkat setelah menggunakan fasilitas akad qard al-ḥasan dari KSP Wanita Maju Jaya, di antaranya adalah semakin banyaknya stok produk usaha, semakin tingginya hasil produktivitas usaha, bertambahnya alat produksi yang dibutuhkan dalam usaha, dan kelengkapan alat pendukung usaha.

\section{Kesimpulan}

Dari penelitian di atas, maka dapat disimpulkan bahwa dengan adanya akad qard alhasan di Koperasi Simpan Pinjam (KSP) Wanita Maju Jaya di Desa Kebalanpelang Babat Lamongan dapat memberikan peningkatan pendapatan para kaum perempuan dan meningkatkan kemajuan usahanya. Dengan cara memberikan pinjaman kepada anggota koperasi yang bertujuan untuk meningkatkan usahanya sehingga pendapatan kaum perempuan juga bisa meningkat dengan baik. Dengan adanya peningkatan pendapatan sekarang, kaum perempuan di Desa Kebalanpelang Babat Lamongan bisa merasa mandiri dan mereka merasa sudah bisa membantu perekonomian keluarganya. Akad qard al-hasan yang diterapkan di KSP Wanita Maju jaya juga dapat meningkatkan kualitas usaha ekonomi para kaum perempuan untuk kesejahteraan kaum perempuan Desa Kebalanpelang Babat Lamongan. Karena dengan adaya akad qard al-ḥasan tersebut adalah salah satu cara untuk membantu dan meringankan beban para kaum perempuan yang mempunyai usaha dalam masalah permodalan yang bertujuan untuk meningkatkan usahanya agar menjadi lebih baik dan berkembang dari sebelumnya, sehingga dengan cara mereka meningkatkan usahanya pendapatan yang mereka miliki juga otomatis ikut meningkat sehingga para kaum perempuan bisa membantu perekonomian keluarga.

\footnotetext{
12 Ibid.
} 


\section{Daftar Rujukan}

Achmad, Muallif. "Pemberdayaan Perempuan Melalui Kelompok Wanita Tani oleh Organisasi Muslimat NU”. Skripsi--UIN Sunan Kalijaga Yogyakarta, 2014.

Ardiyati. "Analisis Pemberdayaan Perempuan Melalui Simpan Pinjam Kelompok", Publikauma: Jurnal Ilmu Administrasi Publik, Volume 6, Nomor 1 (2018).

Burhanudin. "Pemahaman dan Penerapan Qard Al-Hasan pada KJKS BMT Haniva". Skripsi-Universitas Islam Negeri Sunan Kalijaga Yogyakarta, 2012).

Furchan, Arif dan Agus Maimun. Studi Tokoh: Metode Penelitian Mengenai Tokoh. Yogyakarta: Pustaka Pelajar, 2005.

Hanisah, Siti, "Pemberdayaan Perempuan melalui Kegiatan Ekonomi Berkeadilan", Jurnal Perempuan Indonesia, Volume 9, Nomor 1 (Oktober 2013).

Hatneny, Aleria Irma. "Koperasi Wanita dan Pemberdayaan Perempuan dalam Menumbuhkan Ekonomi Kerakyatan di Kota Malang”, JU-ke, Volume 1, Nomer 2 (Desember 2017).

Loveis, Rachmawati. "Peranan Perempuan dalam Ekonomi Keluarga Petani di Desa Puro Karangmalang Sragen”. Skripsi--UIN Sunan Kalijaga Yogyakarta, 2015.

Misbah, T. Lembong. "Pemberdayaan Perempuan Melalui Koperasi Wanita di Banda Aceh", Takammul: Jurnal Studi Gender dan Islam serta Perlindungan Anak, Volume 4, Nomor 2 (Juli-Desember 2015).

Moleong, Lexy J. Metodologi Penelitian Kualitatif. Bandung: PT. Remaja Rosdakarya, 2012. Rafsanjani, Haqiqi dan Rukhul Amin. "Peran Koperasi Wanita dalam Membangun Keuangan Iklusif Syariah”, Jurnal Masharif al-Syariah: Jurnal Ekonomi dan Perbankan Syariah, Volume 2, Nomor 1 (2017).

Sugiyono. Metode Penelitian Kuantitaif Kualitatif dan R\&D. Bandung: Alfabeta, 2010.

Suharsimi, Arikunto. Prosedur Penelitian Suatu Pendekatan Praktis. Jakarta: Renika Cipta, 1991.

Syahriyah, Semaun. "Eksistensi Koperasi Wanita dalam Meningkatkan Pendapatan Masyarakat", Jurnal Al-Maiyyah, Volume 11, Nomor 2 (Juli-Desember 2018).

Tulusan, Femy M.G dan Very Yolanda. "Peningkatan Pendapatan Masyarakat Melalui Program Pemberdayaan di Desa Lolah II Kecamatan Tombariki Kabupaten Minahasa”, Jurnal LPPM Bidang EkoSusBudkum, Volume 1, Nomor 1 (2014).

http://mazdalifahjalil.wordpress.com/2013/01/25/seminar-dan-talkshow-perempuan-danruang-publik/ diakses pada 24 Desember 2019. 